\title{
BALANCE ASSESSMENT AFTER TWO TYPES OF BADMINTON TRAINING
}

\author{
Anna Manolova \\ National Sports Academy "Vassil Levski”, Sofia, Bulgaria
}

\begin{abstract}
Summary:
The purpose of the present study is to investigate the effect of two types of badminton training (specific and technical and tactical) on balance. Taking into account this purpose, 22 young badminton players (age 11 to 15 years) participate in the study. Methodology: Stork balance stand test, modified Bass test and Star excursion balance test were used to determine balance. All subjects performed the tests pre- and post- 60- minute- training session. The two types of training were performed in different days.

Results: At the pre-test significant difference between the right and left foot at the Stork balance stand test and the posterolateral direction of the Star excursion balance test was observed. Significant decrease of the results after both types of training was reported at the modified Bass test, the right leg in the Stork balance test and the left leg's posteromedial direction in the Star excursion test. After 60 minutes of specific training a decrease at the results in anterior direction in the right foot was observed. Only the modified Bass test showed significant differences between the two types of training. Conclusions: This study shows that both trainings lead to decrease of balance ability. Taking this in consideration the balance training should be performed prior to the main part of the training session.
\end{abstract}

Key words: badminton, balance assessment

\section{Introduction}

Nowadays badminton is one of the most popular played racquet sports in the world. The Badminton World Federation (BWF) assessed that about 150 million people play the game and more than 2000 participate in international competitions. It is the fastest racquet sport with a structure characterized by repetitive actions of short duration, requiring compound of speed, power, agility, strength, flexibility and balance ability.

For many years specialists have been interested in the role of balance in performance. Simply, balance can be defined as "the ability to maintain the body's center of gravity within the limits of stability as determined by the base of support" (Yim-Chiplis, 2000). Balance control involves the interaction of the neurologic, musculoskeletal, proprioceptive, vestibular and visual systems. Postural control (balance) can be classified as static and dynamic. Static postural control tries to maintain a base of support while minimizing movement of body segments and the center of mass, and dynamic control involves the completion of a functional task with purposeful movements without compromising an established base of support (Gribble, 2004; Kahle, 2009). Loss of balance during fast side-to-side movements may contribute to lower limb injuries. The lack of balance is often a result from muscular fatigue, which leads to a decrease in neuromuscular control.
Fatigue is defined as a reduction in force production capacity regardless of the performed movements (Erik, 2004). In order to investigate the effects of fatigue on postural control system, different techniques have been used to exhaust body and limbs, specially lower limbs, which include isokinetic contractions (Yaggie, 2002), repetitive motions (Olmsted, 2004), isometric contractions (Forestier, 2002; Sarshin, 2011). But these methods turned out to be not practical and relevant to any kind of sport, so the researches have defined functional fatigue protocols (Aydoğmuş, 2015; Rowe, 1999; Sparto, 1997). Most of the studies which have been reviewed concluded that fatigue resulted in a reduction in postural control.

Performing of badminton skills in a better way during a match requires an advanced function of lower limbs and dynamic postural control. Considering this it is necessary to examine the probable relationship between the whole body fatigue and postural control by using a functional fatigue protocol similar to the badminton and its events (Sarshin, 2011).

\section{Aim of the study}

The purpose of the study is to investigate the effect of the fatigue, induced by two different kinds of badminton specific work, on balance ability. 


\section{Methods}

Participants

Twenty-two young badminton players, aged between 11 and 15 (boys=9, girls=13), agreed to participate in the study. All the participants in the study did not have any health problems or disability, and had at least 1-year prior badminton experience.

\section{Protocol}

Participants attended three training sessions that included assessment of static balance (using the Stork balance stand test), dynamic balance (using the modified BASS test and the Y balance test), and leg length. For assessment of leg length, we used a tape measure to determine the distance (to the nearest millimeter) between the anterior superior iliac spine and the most distal portion of each lateral malleolus of the same leg (Plisky, 2006). At the first training session the participants were given practice trials to become familiar with the testing procedures and at the same session were received the pre-test results. The second session (on the next day) was 60-minute specific badminton training, after which some post-test results were collected. The third session was 60-minute technical and tactical training, after which some post results were also collected.

\section{Procedures}

To perform the Stork balance stand test, each boy or a girl stood first on his dominant foot, with his/her opposite foot against the inside of the supporting knee, and both hands on his hips. At the start signal, each participant raised the heel of the dominant foot from the floor and attempted to maintain balance as long as possible. The trial ended if the participant either moved his hands from his hips, the ball of the dominant foot moved from its original position, or his heel touched the floor. Then the test was done when the boys and girls stood on the other leg. Each participant performed this test three times, with only the best time used in data analysis. The time between trials was within 5 and 10 seconds. Standard protocol for implementing this test suggests stopping the test once a participant achieves the norm of 45 seconds (Hobbs, 2008).

For the modified Bass test, eleven pieces of tape (1" $\mathrm{X} 3 / 4$ ") were placed in the pattern shown in Figure 1 . When ready, the participant: 1) stood with the right foot on the starting mark and the left foot elevated; 2) leapt to the first tape mark, landed on the ball of the left foot, and attempted to hold this position for
5 seconds; 3 ) leapt to the second tape mark, landed on the ball of the right foot, and attempted to hold for 5 seconds; and 4) continued to the other tape marks. The test scoring was following: 5 points for landing successfully on the tape mark; 1 point for each second (up to 5 seconds) the steady position was held on the tape marks. A maximum of 10 points per tape mark and 100 points for the test could have been earned. The participant was not rewarded the 5 points for landing if: fail to stop upon landing; touch the floor with any part other than the ball of the landing foot; fail to completely cover the tape mark. If the participant landed successfully on the tape mark but committed any of the following errors before completing the 5- second count, the point count was immediately stopped: touch the floor with any part other than the ball of the landing foot; fail to hold the landing foot steady (Tsigilis, 2001).

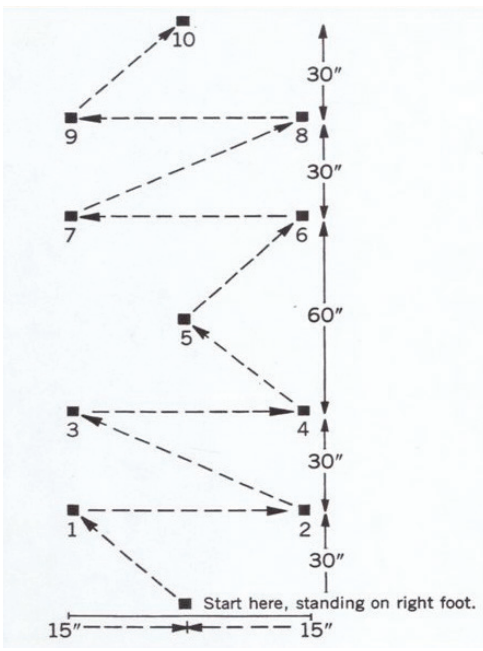

Figure 1 - Modified BASS Test

For the $\mathrm{Y}$ balance test participants stood on one leg on a center of $Y$ - Junction shape surface. While maintaining single-leg stance, the player was asked to reach with the free limb in the anterior, posteromedial, and posterolateral directions in relation to the stance foot. The maximal reach distance was measured by marking the tape measure with erasable ink at the point where the most distal part of the foot reached. The trial was discarded and repeated if the player: fail to maintain unilateral stance; lift or move the stance foot from the grid; touch down with the reach foot; fail to return the reach foot to the starting position. The process was repeated while standing on the other leg. The greatest of 3 trials for each reach direction was used for analysis of the reach distance in each direction (Plisky, 2006). 


\section{Training protocols}

- Specific badminton training (60 minutes) at this session were included: 5 min of slow running/ 2-3 min for warm up of all body segments/ ladder work (10 exercises $\mathrm{x} 3$ times/ repeat)/ clock face jumps - 3 times in a roll/ 6 point shadowing partner (unpredictable) (10 times $\mathrm{x} 15 \mathrm{sec}$ )/ cone work/ multi shuttle - full court, 5 times $\mathrm{x} 20$ shuttles/ 2 against 1 exercises - 7 minutes/ 3 against 2 exercises -7 minutes;

- Technical and tactical training protocol $(60$ minutes): 5 min of slow running/ 2-3 min for warm up of all body segments/ match on a half court - to 11 points with 4 different opponents, 2 games on forehand side and 2 on backhand side, without smash/ single math - each game with different opponent (the number of games depends on the remaining time)

\section{Statistical Analyses}

Data were analyzed using SPSS Version 16.0 software. Descriptive statistics (Mean $\pm \mathrm{SD}$ ) were calculated for all variables. Data from pre-test and post-test and between the two different training protocols were compared with Pared Samples T test. Statistical significance was set at $\mathrm{p} \leq 0.05$.

\section{Results}

The aim of the study is to investigate the effect of the fatigue on balance ability. The statistical analyses on pre- and post-test data show a significant difference after both types of training in the BASS test (table 1), the right leg in the Stork balance stand test (table 2) and the left leg's posteromedial direction in the Star excursion test (table 3).

Table 1. Pre- and Post-test comparisons for the BASS test

\begin{tabular}{|l|l|l|l|l|l|}
\hline \multicolumn{1}{|c|}{ BASS } & $\mathbf{n}$ & $\begin{array}{l}\text { Pre-test } \\
\text { Mean } \pm \text { SD }\end{array}$ & $\begin{array}{l}\text { Post-test } \\
\text { Mean } \pm \text { SD }\end{array}$ & t value & $\mathbf{P}(\mathbf{t})$ \\
\hline Before and after ST & 22 & $81.59 \pm 6.06$ & $66.184 .09 \pm$ & 13.14 & $100.00^{*}$ \\
\hline Before and after TTT & 22 & $81.59 \pm 6.06$ & $72.64 \pm 5.38$ & 7.99 & $100.00^{*}$ \\
\hline
\end{tabular}

ST - specific training; TTT - technical and tactical training

* Statistically significant relationships

Table 2. Pre- and Post-test comparisons for the Stork balance stand test

\begin{tabular}{|c|l|l|l|l|l|l|}
\hline \multicolumn{2}{|l|}{ Stork balance stand test } & n & $\begin{array}{l}\text { Pre-test } \\
\text { Mean } \pm \text { SD }\end{array}$ & $\begin{array}{l}\text { Post-test } \\
\text { Mean } \pm \text { SD }\end{array}$ & t value & P $(t)$ \\
\hline \multirow{2}{*}{ Before and after ST } & Left leg & 22 & $3.86 \pm 1.74$ & $3.39 \pm 1.57$ & 1.57 & 86.78 \\
\cline { 2 - 8 } & Right leg & 22 & $5.16 \pm 2.68$ & $3.36 \pm 1.18$ & 3.40 & $99.73^{\star}$ \\
\hline \multirow{2}{*}{ Before and after TTT } & Left leg & 22 & $3.86 \pm 1.74$ & $3.55 \pm 1.63$ & 1.04 & 69.12 \\
\cline { 2 - 7 } & Right leg & 22 & $5.16 \pm 2.68$ & $3.28 \pm 1.13$ & 3.59 & $99.83^{\star}$ \\
\hline
\end{tabular}

ST - specific training; TTT - technical and tactical training

* Statistically significant relationships

After 60- minute specific training a decrease at the results in anterior direction in right foot is observed (table 3).

Table 3. Pre- and Post-test comparisons for the Star excursion balance test

\begin{tabular}{|l|l|l|l|l|l|l|l|}
\hline \multicolumn{2}{|l|}{ Star excursion balance test } & Direction & n & $\begin{array}{l}\text { Pre-test } \\
\text { Mean } \pm \text { SD }\end{array}$ & $\begin{array}{l}\text { Post-test } \\
\text { Mean } \pm \text { SD }\end{array}$ & t value & P (t) \\
\hline $\begin{array}{l}\text { Before and } \\
\text { after ST }\end{array}$ & Right leg & Anterior & 22 & $76.64 \pm 8.77$ & $73.829 .36 \pm$ & 2.44 & $97.63^{*}$ \\
\cline { 2 - 8 } & Left leg & Post. medial & 22 & $80.23 \pm 11.14$ & $76.27 \pm 9.65$ & 3.17 & $99.53^{\star}$ \\
\hline $\begin{array}{l}\text { Before and } \\
\text { after TTT }\end{array}$ & Right leg & Anterior & 22 & $75.36 \pm 9.72$ & $73.82 \pm 9.36$ & 1.16 & 74.11 \\
\cline { 2 - 8 } & Left leg & Post. medial & 22 & $80.23 \pm 11.14$ & $76.95 \pm 9.09$ & 2.42 & $97.54^{*}$ \\
\hline
\end{tabular}

ST - specific training; TTT - technical and tactical training

* Statistically significant relationships The BASS test and right's leg anterior direction in the Star excursion balance test show a significant difference in the post-result between the two different training protocols (table 4). 
Table 4. Differences in the post-test results after the two types of training

\begin{tabular}{|l|l|l|l|l|l|}
\hline & $\mathbf{n}$ & $\begin{array}{l}\text { After ST } \\
\text { Mean } \pm \text { SD }\end{array}$ & $\begin{array}{l}\text { After TTT } \\
\text { Mean } \pm \text { SD }\end{array}$ & t value & P (t) \\
\hline BASS & 22 & $66.18 \pm 4.09$ & $72.64 \pm 5.38$ & 11.27 & $100.00^{\star}$ \\
\hline SEBT; right leg; anterior direction & 22 & $76.64 \pm 8.77$ & $75.36 \pm 9.72$ & 2.26 & $96.55^{\star}$ \\
\hline
\end{tabular}

ST - specific training; TTT - technical and tactical training

SEBT - Star excursion balance test

* Statistically significant relationships Discussion

At the pre-test results we see a difference between the right and the left foot in the Stork balance stand test and the posterolateral direction in the Star excursion balance test. We can explain these results with the biomechanical characteristics of the sport and the dominance of one of the legs. Regardless of the fact that the exercises are fulfilled bilateral so the both limbs can be properly trained, there are still bigger loads at the dominant leg during the game.

A first observation is that the fatigue has an initial effect on the control of balance; it yielded a significant decrease of the results in the BASS test, which is a test for accuracy and endurance. This decline of performance agrees with previous studies concerning the effect of strenuous fatigue on the control of upright standing posture (Yaggie, 2002). Decreases in the results in the Star excursion balance test (SEBT) are also observed from Sarshin et al. (2007) and Plisky et al. (2006). They found out that the neuromuscular inefficiency resulting from fatigue has an undesirable effect on the control role of the lower limb muscles responsible for the reaching distance. Moreover, the fatigue protocol can affect muscles' co - contraction which is necessary in performing reaching in SEBT and it can create some disorders in doing the act of reaching. The observed reduction of the results in the Stork balance stand test could result from muscular fatigue resulting from proprioceptive deficit in muscle receptors and loss of muscular reflexes responsible for dynamic joint stability (Fabunmi, 2011). According to Simoneau et al. with fatigue, muscle spindles tend to decrease their firing rate and the cortico-motor neuronal cells firing decreases and become more irregular, also fatigue induces greater variability or noise in the afferent signal and these initial changes could result in a poorer detection of the CP position (Simoneau, 2006).

There is a reduction in the balance performance after fatiguing exercises which leads to a bigger risk of injuries. Applying good exercise bouts which are conformed to the involving models during a badminton match or training are recommended in order to reduce fatigue experience and improve physical fitness. It is also advisable to include balanced exercises in badminton training to minimize the risk of falls and injuries.

\section{Acknowledgements}

With gratitude to Badminton club NSA "V. Levski", Badminton club "Pobeda", Dupnitsa and associate professor Aneta Yaneva.

\section{References}

Aydoğmuş, M., Aarslanoğlu, E., Özmen, T., Effect of badminton specific training versus badminton match on aerobic fitness, The Online Journal of Recreation and Sport, 2015, Volume 4, Issue 2

Erik, A. et al., Dynamic stabilization time after isokinetic and functional fatigue, J Athl Train, 2004, Volume 39

Fabunmi, A., Lesi, A., Akosile, O., Effect of exercise induced fatigue on standing balance performance, The 53rd ICHPER.SD Anniversary World Congress, Egypt, 2011

Forestier, N., Teasdale, N. and Nougier, V., Alteration of the position sense at the ankle induced by muscular fatigue in humans, Med Sci Sports Exerc, 2002, Volume 34 Gribble, P. et al., The effects of fatigue and chronic ankle instability on dynamic postural control, J Athl Train. 2004, Volume 39

Hobbs, M., Dynamic balance and basketball playing ability, 2008, Thesis for the degree Master of education, San Marcos, TX

Kahle, N., The effects of core stability training on balance testing in young, healthy adults, 2009, Thesis for the Bachelor science degree, University of Toledo

Olmsted, L., Hertel, J., Influence of foot type and orthotics on static and dynamic postural control, J Sport Rehab, 2004, Volume 13

Plisky, Ph. et al., Star excursion balance test as a predictor of lower extremity injury in high school basketball players, Journal of Orthopedic \& Sports Physical Therapy, 2006, Volume 36, Issue 12

Rowe, A. et al., Effects of a 2-hour cheerleading practice on dynamic postural stability, knee laxity and Hamstring extensibility; Journal of Orthopedic \& Sports Physical Therapy 1999, Volume 29

Sarshin, A. et al., The effect of activity related fatigue 
on dynamic postural control as measured by the Star matics, coordination, and postural stability during a reexcursion balance test, Journal of Biomechanics, 2007, petitive lifting task, J Orthop Phys Ther, 1997, Volume 25 Volume 40 Tsigilis, N., Zachopoulou, E., Mavridis, T., Evaluation of

Sarshin, A. et al., The effects of functional fatigue on dythe specificity of selected dynamic balance tests, Percepnamic postural control of badminton players, Biology of exercise, 2011, Volume 7.2 tual and Motor Skills, 2001, Volume 92

Simoneau, M., Bégin, F., Teasdale, N., The effects of Yaggie, J., McGregor, S., Effects of isokinetic ankle famoderate fatigue on dynamic balance control and attentional demands, Journal of NeuroEngineering and Rehabilitation, 2006, 3:22

Sparto, P. et al., The effect of fatigue on multijoint kinetigue on the maintenance of balance and postural limits, Arch Phys Med Rehabil, 2002, Volume 83

Yim-Chiplis, P., Talbot, L. Defining and measuring balance in adults, Bio Rsrch for Nurs. 2000, Volume 1 